\title{
Intensional Choice Functions for Which Phrases
}

\author{
Maribel Romero \\ University of Pennsylvania
}

\section{Introduction}

There are two main approaches to the scopal properties of the N'-restrictors of which-phrases. One line attributes widest scope within the interrogative clause to the entire which-phrase, outside the question formation operator, often assumed to reside in $\mathrm{C}^{0}$. The result is Karttunen's (1977) question denotation --exemplified in (1b)--, whose distinctive feature is that the semantic contribution of the N'restrictor of the which-phrase is represented outside the so-called question nucleus, i.e., outside the subformula " $\mathrm{p}=$...". The second main avenue interprets the N'-restrictor of which-phrases somewhere inside the question nucleus, that is, under the scope of the question formation operator and possibly under other, further embedded operators. The outcome is Hamblin's (1973) --or unselective binding-question meaning, as in (1c). This paper will be concerned with this second line, which I will refer to as the base position line (as opposed to wide scope line).

a. Which professor did Sonia upset?

b. Wide scope line: $\lambda w \lambda p . \exists x\left[\operatorname{professor}(x)(w) \& p=\lambda w^{\prime} \cdot \operatorname{upset}(x)(s)\left(w^{\prime}\right)\right]$

c. Base position line:

$$
\lambda w \lambda p . \exists x\left[p=\lambda w^{\prime} \cdot \operatorname{professor}(x)\left(w^{\prime} / w\right) \& \operatorname{upset}(x)(s)\left(w^{\prime}\right)\right]
$$

This first version of the base position line faces some challenges.

First, Reinhart (1992) observes that interpreting N'-restrictors of which phrases in the base position line sometimes yields truth conditions that are too weak. For example, the base position approach predicts (2b) to be a possible question meaning for $(2 \mathrm{a})$. Making the standard assumption that each proposition in the denotation of a question (in a given $w$ ) is a felicitous (true or false) answer to that question (in w) (see, e.g., Hamblin (1973:52)), (2b) wrongly preditcs (2c) or the abridged (2d) to be an acceptable answer to the interrogative (2a). ${ }^{2}$

(2) a. Who would be upset if we invited which philosopher? (Reinhart 1992)

b. $\lambda w \lambda p . \exists x y\left[p=\lambda w^{\prime} . \forall w^{\prime \prime}\left[\left[\operatorname{invite}(y)(w e)\left(w^{\prime \prime}\right) \&\right.\right.\right.$ philosopher(y)(w/w'/w") \& w" is (maximally) similar to $w^{\prime}$ in any other respect] $\left.\left.\rightarrow \operatorname{upset}(\mathrm{x})\left(\mathrm{w}^{\prime \prime}\right)\right]\right]$

c. \# Patricia would be upset if we invited Donald Duck and Donald Duck is (w) / was (w") a philosopher.

d. \# Patricia would be upset if we invited Donald Duck. 
Second, so-called functional readings are not yet captured (under neither line). So far, the propositions in the question denotation are built by quantifying over a variable of individual type. Such representation elicits the individual answer (3b), but it does not account for the functional answer (3c) (Engdahl 1980, 1986).

a. Which classmate of theirs do most kids like best?

b. Mireia.

c. Their deskmate. (i.e., each kid likes a different classmate best)

To solve both problems at once, the base position line utilizes choice functions and relativizes them to a given world. ${ }^{3}$ The current choice function analysis can be summarized as follows.

Which-phrases range over choice functions (Engdahl 1980, Reinhart 1992 for which-phrases; see also Matthewson 1999, Kratzer 1998, Reinhart 1997 and Winter 1997 for indefinites). ${ }^{4}$ The basic notion of choice function is defined under (4) and its use is exemplified under (5):

(4) (Partial) Basic Choice Function definition:

(Kratzer 1998:167)

A function $\mathrm{f}$ is a choice function $(\mathrm{CH}(\mathrm{f}))$ if, for every set $\mathrm{P}$ in its domain, $f(P)$ is a member of $P$.

a. Who remembers who ${ }_{1}$ would be offended if we invited which of her 1 philosophical rivals?

b. $\lambda \mathrm{w}_{1} \lambda \mathrm{p} . \exists \mathrm{g}, \mathrm{f}\left[\mathrm{CH}(\mathrm{g}) \& \mathrm{CH}(\mathrm{f}) \& \mathrm{p}=\lambda \mathrm{w}_{2} . \mathrm{g}\right.$ (person) remembers in $\mathrm{w}_{2}$ $\left(\lambda \mathrm{w}_{3} \lambda \mathrm{q}: \exists \mathrm{h}\left[\mathrm{CH}(\mathrm{h}) \quad \& \quad \mathrm{q}=\lambda \mathrm{w}_{4} . \forall \mathrm{w}_{5}[\right.\right.$ invite(f([Iphilosophical rival of hers 1$\left.\left.]]^{g^{\prime}(\text { person)/1 }}\left(w_{1 / 2 / 3 / 4 / 5}\right)\right)\right)\left(w_{e}\right)\left(w_{5}\right) \& w_{5}$ is (maximally) similar to $w_{4}$ in any other respect $\rightarrow$ offended $\left(h(\right.$ person $\left.\left.)\left(w_{5}\right)\right]\right]$ ) ]

Note that nothing prevents us, in principle, from evaluating the N'restrictor (one) of her philosophical rivals with respect to any of the world variables in the formula $(5 b)$. Reinhart $(1992,1997)$ notes that this is a dangerous situation, since picking $\mathrm{w}_{5}$ would bring us back to the weak truth condition problem: we should be able to choose a non-actual philosophical rival of $g(1)$ for our answer as long as that individual is a philosophical rival of $g(1)$ in $w_{5}$. Given that this is contrary to intuitions, that is, given that the choice function seems to be forced to choose from the actual rivals -which I will call Transparency Effect--, a new notion of "choice" function is put forward and relativized to a given world, as in (6) (von Stechow 1996, formalizing Reinhart 1992). Note that now the domain of the choice function does not contain extensional sets, ${ }^{5}$ but properties. No matter how intensionally embedded $\mathrm{f}\left(\mathrm{P}_{<\mathrm{s}, \mathrm{et}}\right)$ is, $\mathrm{f}(\mathrm{P})$ yields an element of $\mathrm{P}(\mathrm{w})$, where $\mathrm{w}$ is the evaluation world of the question. (5b') is the new question meaning for (5a).

(6) (Partial) Relativized "Choice" function wrt w: (von Stechow 1996:13)

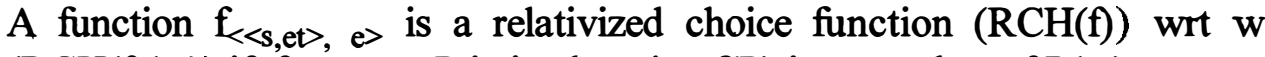
$(\mathrm{RCH}(\mathrm{f})(\mathrm{w}))$ if, for every $\mathrm{P}$ in its domain, $\mathrm{f}(\mathrm{P})$ is a member of $\mathrm{P}(\mathrm{w})$. 
b'. $\lambda w_{1} \lambda p \cdot \exists g, f \quad\left[R C H(g)\left(w_{1}\right) \& \operatorname{RCH}(f)\left(w_{1}\right) \& p=\lambda w_{2} \cdot g(\right.$ person) remembers in $\mathrm{w}_{2}$

$\left(\lambda \mathrm{w}_{3} \lambda \mathrm{q}: \exists \mathrm{h}\left[\mathrm{RCH}(\mathrm{h})\left(\mathrm{w}_{3}\right) \& \mathrm{q}=\lambda \mathrm{w}_{4} . \forall \mathrm{w}_{5}[\right.\right.$ invite (f([Iphilosophical rival of hers $\left.\left.]_{1}\right]^{g^{\prime} h(\text { person)/1 }}\right)\left(w_{e}\right)\left(w_{5}\right) \& w_{5}$ is (maximally) similar to $w_{4}$ in any other respect $\rightarrow$ offended(h(person $\left.\left.)\left(\mathrm{w}_{5}\right)\right]\right]$ ] ]

There is yet another circumstance to consider: what happens if the N'restrictor denotes the empty set in the question evaluation world, as in (7a)? Two main strategies are possible. The first one is to consider that choice functions are partial -as in the definitions so far-- and that the empty set is not in their domain. This predicts that (7a) is unfelicitous in the actual world $w_{0}$, given that there is no felicitous answer for it in $\mathrm{w}_{0}{ }^{6}$ The second strategy maintains that choice functions are total functions and that they yield a falsifying object when the N'-restrictor denotes the empty set, as suggested in von Stechow (1996:4f), Reinhart (1997:391ff) and Winter (1997:434ff). For the sake of illustration, I spell out von Stechow's implementation of this strategy under (8). Here, the prediction is that all propositions in $[[(7 \mathrm{a})]]\left(\mathrm{w}_{0}\right)$ will constitute trivially true answers, since all of them arise from computing the false antecedent of a conditional. ${ }^{7}$

a. Who checked every law that which American king had sanctioned?

b. $\lambda \mathrm{w}_{1} \lambda \mathrm{p} \cdot \exists \mathrm{g}, \mathrm{f}\left[\mathrm{RCH}(\mathrm{g})\left(\mathrm{w}_{1}\right) \& \mathrm{RCH}(\mathrm{f})\left(\mathrm{w}_{1}\right) \& \mathrm{p}=\lambda \mathrm{w}_{2} \cdot \forall \mathrm{x}\left[\left(\mathrm{law}(\mathrm{x})\left(\mathrm{w}_{2}\right) \&\right.\right.\right.$ sanction $(\mathrm{x})(\mathrm{f}($ American king $\left.))\left(\mathrm{w}_{2}\right)\right) \rightarrow \operatorname{checked}(\mathrm{x})(\mathrm{g}($ person $\left.\left.))\left(\mathrm{w}_{2}\right)\right]\right]$

(8) Total Relativized "Choice" function wrt w:

A function $\mathrm{f}_{<<, e t>, e>}$ is a relativized choice function wrt $\mathrm{w}(\mathrm{RCH}(\mathrm{f})(\mathrm{w}))$ iff:

(i) $\mathrm{f}(\mathrm{P})$ is a member of $\mathrm{P}(\mathrm{w})$, if $\mathrm{P}(\mathrm{w})$ is non-empty, and

(ii) $(\mathrm{P})=*$ (the absurd individual, which is not in any natural language denotation), if $\mathrm{P}(\mathrm{w})$ is empty. (adapted from von Stechow 1996)

The main goal of this paper is to argue for a new architecture of choice functions that follows the basic choice function idea, but implements it with a higher type: <<se,t>, <se >>. The new proposal will be argued for in section 2 in two steps. First, based on examples of local presupposition accommodation (Romero 1997), I will conclude that choice functions yield individual concepts more often than we thought, that is, that we need intensional choice functions even when there is no intensional operator embedded in the interrogative clause. As a corollary, the problem of empty N'-restrictors does not arise anymore. Second, from examples of which-phrases with transparent restrictor eliciting intensional answers, I will conclude that we need a new definition of intensional choice functions, closer to the basic choice funtion idea.

A secondary, tentative goal of this paper is to shed some suspicion over the alleged Transparency Effect of which-phrases. In section 3, I will show that, in Spanish, despite the fact that transparency effects often obtain, there are some indicators that N'-restrictors of qué-phrases can be opaque: Subjunctive Relative Clauses in Spanish. 


\section{The Need of Intensional Choice Functions}

\subsection{Local Presuppasition Cases}

The following examples --(9) and, in the scenario depicted in (10), (11)-- involve local accommodation of the existence presuppositions triggered by the definite NPs his younger sister and his $s_{1}$ dog, namely the presuppositions "that there is a (unique) $y$ that is $\mathrm{g}(1)$ 's younger sister" and "that there is a y that is $\mathrm{g}(1)$ 's dog".

(9) a. Mary didn't assume that any boy ${ }_{1}$ in the class would bring his ${ }_{1}$ younger sister --since she knows that no boy in the class has a younger sister.

b. $\lambda w . \neg\left[M a r y\right.$ assumed in $w\left(\lambda w^{\prime} . \exists x\left[b o y(x)\left(w^{\prime}\right) \& \exists y\left[\operatorname{sister}(x)(y)\left(w^{\prime}\right)\right.\right.\right.$ $\left.\left.\& \operatorname{brought}(\mathbf{y})(\mathbf{x})\left(\mathbf{w}^{\prime}\right)\right]\right]$ )]

(10) Scenario for (11):

We know that Lucie gets really mad at boys mistreating their dogs, to the point that she screams at them until she gets a sore throat. We don't know what pets the boys at today's contest own (i.e., as far as we know, there may not be any dog-owning boy). We just know that, after the contest, her voice is in good condition. We estimate that there must have been at most one misbehaved dog-owning-boy, if any.

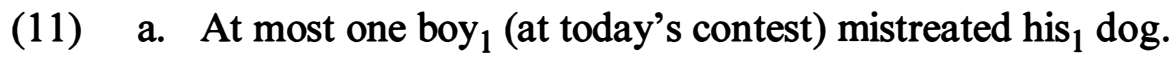

b. $\lambda w . \exists_{\leq 1} x[\operatorname{boy}(x)(w) \& \exists y[\operatorname{dog}-o f(x)(y)(w) \& \operatorname{mistreated}(y)(x)(w)]]$

Parallel examples of local presupposition accommodation can be constructed with which phrases, too:

(12) Q: Who didn't assume that any boy ${ }_{1}$ in the class would bring which relative of his ${ }_{1}$--since that person knew that no boy in the class has such a relative?

A: $\sqrt{ }$ Mary didn't assume that any boy ${ }_{1}$ in the class would bring his younger sister --since Mary knows that no boy in the class has a younger sister.

(13) Q: Which pet of his 1 did at most one boy (at today's contest) mistreat?

A: (At most one boy ${ }_{1}$ at today's contest mistreated) his dog. $_{1}$

The current extensional choice function approaches do not account for these local presupposition readings. If we take basic or relativized choice functions to be total functions (Reinhart 1997 for indefinites), then we cannot generate these readings. For the sake of illustration, let us see what happens if we try to generate a question denotation for (13Q) that contains the proposition expressed by the felicitous answer (13A). I will exemplify it under the relativized choice function approach, but the same reasoning carries over to basic choice functions. First, we 
need a total choice function that picks dogs whenever possible but is still defined otherwise; that is, we need a function along the lines described in (14). Then, after computing the question meaning -as in (15b)--, we take the function $f_{\text {dog }}$ in (14) and obtain the proposition in (15c) as a member of $[[(13 Q)]]\left(w_{0}\right)$. The problem is that $(15 \mathrm{c})$ does not even come close to the proposition expressed by $(13 \mathrm{~A})$, which we are trying to generate. More specifically, if, in the actual world $w_{0}$, none of the relevant boys owned a dog but they all mistreated all their existing pets, $[[(13 \mathrm{~A})]]\left(\mathrm{w}_{0}\right)=1$ and $(15 \mathrm{c})\left(\mathrm{w}_{0}\right)=0$.

Example of total choice function, where $\mathrm{RCH}\left(\mathrm{f}_{\mathrm{dog}}\right)\left(\mathrm{w}_{0}\right)$ :

$\mathrm{f}_{\mathrm{dog}}$ : for all the $\mathrm{N}^{\prime} P$ and for all relevant individuals $\mathrm{x}$ :

$\mathrm{f}_{\operatorname{dog}}\left(\left[\left[P \text { of } h i s_{1}\right]\right]^{\mathrm{gx} / 1}\right)=\mathrm{x}$ 's dog if there is a (unique) dog of $\mathrm{x}$ in $[[P$ of his 1$]]\left(\mathrm{w}_{0}\right)$;

$\mathrm{f}_{\mathrm{dog}}\left(\left[\left[P \text { of } h i_{1}\right]\right]^{\mathrm{gx} / 1}\right)$ yields some other member of $\left[\left[P\right.\right.$ of $\left.\left.h i s_{1}\right]\right]\left(\mathrm{w}_{0}\right)$ otherwise.

(15) a. Which pet of his 1 did at most one boy mistreat? $_{1}$

b. $\lambda w \lambda$ p. $\exists f\left[\operatorname{RCH}(f)(w) \& p=\lambda w^{\prime} . \exists_{\leq 1} x\left[\operatorname{boy}(x)\left(w^{\prime}\right) \&\right.\right.$ mistreat $(\mathrm{f}($ pet of $\left.\left.\mathrm{x}))(\mathrm{x})\left(\mathrm{w}^{\prime}\right)\right]\right]$

c. $\lambda w^{\prime} . \exists_{\leq 1} x\left[\operatorname{boy}(x)\left(w^{\prime}\right) \& \operatorname{mistreat}\left(f_{d o g}(\right.\right.$ pet of $\left.\left.x)\right)(x)\left(w^{\prime}\right)\right]$

Extending the two strategies for empty N'-restrictors to these examples will not yield the right result, either, as I noted in Romero (1997). These strategies will overgenerate local presupposition accommodation readings, creating the very same problem that choice functions were meant to avoid: the problem of weak truth conditions. Let us briefly see why this is so.

Let us try the partial choice function strategy first.

If we allow for partial relativized choice functions, like the ones described under (16), we have that, e.g., the term $f_{\text {dog }}\left(\left[\left[\right.\right.\right.$ pet of his $\left.\left.{ }_{1}\right]\right]$ ) $)$ carries the presupposition that there is a (unique) dog of $\mathrm{g}(1)$ in $[[$ pet of his $]]] \mathrm{g}\left(\mathrm{w}_{0}\right)$. The local accommodation reading of such presupposition is captured in the question meaning $(17 b)$ by inserting the subformula $\exists y[f($ pet of $x)=y]$. Hence, if we take the partial $\mathrm{f}_{\text {dog }}$ as a value for $f$, we generate the proposition (17c) --paraphrased in $\left(17 c^{\prime}\right)$ for perspicuity-- as a member of $[[(17 a)]]\left(w_{0}\right)$. And, since $(17 c)$ is arguably the proposition expressed by (some reading of) the answer (13A), (13A) is rendered as felicitous answer to (13Q). So far, this is a welcome result.

(16) Examples of partial choice functions, where $\operatorname{RCH}\left(f_{d o g}\right)\left(w_{0}\right)$ and $\mathrm{RCH}\left(\mathrm{f}_{\mathrm{HB}}\right)\left(\mathrm{w}_{0}\right)$, for the actual world $\mathrm{w}_{0}$ :

$\mathrm{f}_{\mathrm{dog}}$ : for all the $\mathrm{N}^{\prime} P$ and for all relevant individuals $\mathrm{x}$ :

$\mathrm{f}_{\mathrm{dog}}\left(\left[\left[P \text { of } h i s_{l}\right]\right]^{\mathrm{gx} / 1}\right)=\mathrm{x}^{\prime} \mathrm{s}$ dog if there is a (unique) dog of $\mathrm{x}$ in $[[P$ of his 1$]]\left(\mathrm{w}_{0}\right)$;

$\mathrm{f}_{\mathrm{dog}}\left(\left[\left[P \text { of his }{ }_{1}\right]\right]^{\mathrm{gx} / 1}\right)$ is undefined otherwise.

$\mathrm{f}_{\mathrm{HB}}$ : for all the $\mathrm{N}^{\prime} P$ and for all relevant individuals $\mathrm{x}$ : 
$\mathrm{f}_{\mathrm{HB}}\left(\left[\left[P \text { of } h i s_{1}\right]\right]_{\mathrm{gx} / 1}\right)=$ Humphrey Bogart if Humphrey Bogart is in $[[P$ of his $\left.\left.{ }_{1}\right]\right]\left(\mathrm{w}_{0}\right)$; $\mathrm{f}_{\mathrm{HB}}\left(\left[\left[P \text { of } h i s_{1}\right]\right]^{\mathrm{g} / 1}\right)$ is undefined otherwise.

a. Which pet of his ${ }_{1}$ did at most one boy mistreat? $_{1}$

b. $\lambda w \lambda p . \exists f\left[\operatorname{RCH}(f)(w) \& p=\lambda w^{\prime} . \exists_{\leq 1} x\left[\operatorname{boy}(x)\left(w^{\prime}\right) \& \exists y[f(p e t\right.\right.$ of $\mathrm{x})=\mathrm{y} \&$ mistreat $\left.\left.(\mathrm{y})(\mathrm{x})\left(\mathrm{w}^{\prime}\right)\right]\right]$ ] ]

c. $\lambda w^{\prime} . \exists_{\leq 1} x\left[b o y(x)\left(w^{\prime}\right) \& \exists y\left[f_{\text {dog }}(\right.\right.$ pet of $\left.\left.x)=y \& \operatorname{mistreat}(y)(x)\left(w^{\prime}\right)\right]\right]$

c'. The proposition "that there is at most one boy among whose actual pets there is one chosen by $f_{\text {dog }}$ and mistreated by him".

The problem is that, by the same token, we can pick $\mathrm{f}_{\mathrm{HB}}$ in (16) as the value of $f$ and locally accommodate the presupposition of the resulting term $\mathrm{f}_{\mathrm{HB}}\left(\left[\left[\text { pet of } h i s_{1}\right]\right]^{\mathrm{g}}\right)$, that is, the presupposition that $\mathrm{H}$. Bogart is in [[pet of $\left.\left.h i s_{1}\right]\right] \mathrm{g}\left(\mathrm{w}_{0}\right)$. Note that the only explicit restriction on possible values for $f$ in the question meaning (17b) is that that value be a $\mathrm{RCH}$ with respect to the evaluation world of the question. Hence, if we evaluate the question under $\mathrm{w}_{0}$, the function $\mathrm{f}_{\mathrm{HB}}$ described in (16) is as good a value for $f$ as $\mathrm{f}_{\mathrm{dog}}$ was. Also, it is difficult to find an implicit contextual restriction that would rule $\mathrm{f}_{\mathrm{HB}}$ out and $\mathrm{f}_{\mathrm{dog}}$ in, since, in principle, a function choosing $\mathrm{H}$. Bogart is as plausible as a function choosing a dog. In sum, there is no overt nor covert restriction that prevents us from generating (17d) -paraphrased in (17d')- as a member of $[[(18 Q)]]\left(w_{0}\right)$, and, thus, we elicit (18A-A') in their local accommodation reading as felicitous (even true) answers to (18Q) (cf. (2c) and fn. 2). This is an unwelcome result.

d. $\lambda w^{\prime} . \exists_{\leq 1} x\left[\operatorname{boy}(x)\left(w^{\prime}\right) \& \exists y\left[f_{H B}(\right.\right.$ pet of $x)=y \&$ mistreat $\left.\left.(y)(x)\left(w^{\prime}\right)\right]\right]$

$d$ '. The proposition "that there is at most one boy among whose actual pets there is one chosen by $f_{\mathrm{HB}}$ and mistreated by that boy".

(18) Q: Which pet of his ${ }_{1}$ did at most one boy (at today's contest) mistreat?

A: \# (At most one boy mistreated) his $_{1}$ pet Humphrey Bogart.

A': \# (At most one boy ${ }_{1}$ mistreated) Humphrey Bogart.

Let me note that this is exactly the same problem of weak truth conditions that we encountered at the beginning of this paper. If the reader has the patience to compare the question meaning at issue (17b) with (2b), she will recognize the same problematic configuration: we existentially quantify over objects of a certain semantic type with no overt nor obvious covert restriction. It is only in an embedded position in the formula that the desired restriction -being someone's philosophical rival or being a function with the property $\left.\left[[\text { relative of his }]_{1}\right]\right]^{\mathrm{g}}$ in its domain--is predicated of the variable. This generates weak truth conditions, predicting non-sensical answers to be felicitous. ${ }^{9}$

As for the falsifying object strategy, the same argument can be constructed against it. The relevant choice functions will now be total functions, as described in (19): when the function cannot select a certain individual, it selects the absurd 
individual, i.e., the individual that, when combined with any predicate denotation, yields 0 . Note the new question meaning spelled out in (20b) and compare it with the former, (17b). Given the import of the absurd individual, the subformula mistreat $(f($ pet of $x))(x)\left(w^{\prime}\right)$ in (20b) has exactly the same truth conditions as the subformula $\exists y\left[f(\right.$ pet of $x)=y \&$ mistreat $\left.(y)(x)\left(w^{\prime}\right)\right]$ in $(17 b)$. Hence, the argument above applies straightforwardly.

(19) Extension of the absurd individual strategy, where $\operatorname{RCH}\left(f_{d o g}\right)\left(w_{0}\right)$ and $\mathrm{RCH}\left(\mathrm{f}_{\mathrm{HB}}\right)\left(\mathrm{w}_{0}\right)$, for the actual world $\mathrm{w}_{0}$ :

$\mathrm{f}_{\text {dog }}$ : for all the $\mathrm{N}^{\prime} P$ and for all relevant individuals $\mathrm{x}$ :

$\mathrm{f}_{\operatorname{dog}}\left(\left[\left[P \text { of } h i s_{1}\right]\right]^{\mathrm{gx} / 1}\right)=\mathrm{x}$ 's dog if there is a (unique) dog of $\mathrm{x}$ in $[[P$ of his 1$]]\left(\mathrm{w}_{0}\right)$;

$\mathrm{f}_{\mathrm{dog}}\left(\left[\left[P \text { of } \text { his }_{1}\right]\right]^{\mathrm{gx} / 1}\right)=$ the absurd individual otherwise.

$\mathrm{f}_{\mathrm{HB}}$ : for all the $\mathrm{N}^{\prime} P$ and for all relevant individuals $\mathrm{x}$ :

$\mathrm{f}_{\mathrm{HB}}\left(\left[\left[P \text { of } h i s_{1}\right]\right]^{\mathrm{gx} / 1}\right)=$ Humphrey Bogart if $\mathrm{HB}$ is in $\left[\left[P\right.\right.$ of his $\left.\left.{ }_{1}\right]\right]\left(\mathrm{w}_{0}\right)$; $\mathrm{f}_{\mathrm{HB}}\left(\left[\left[P \text { of } h i s_{1}\right]\right]^{\mathrm{gx} / 1}\right)=$ the absurd individual otherwise.

(20) a. Which pet of his ${ }_{1}$ did at most one boy ${ }_{1}$ mistreat?

b. $\lambda w \lambda$ p. $\exists f\left[\operatorname{RCH}(f)(w) \& p=\lambda w^{\prime} . \exists_{\leq 1} x\left[b o y(x)\left(w^{\prime}\right) \&\right.\right.$ mistreat(f(pet of $\left.\mathbf{x}))(\mathrm{x})\left(\mathbf{w}^{\prime}\right)\right]$ ]

In sum, we have seen that (extensional) basic and relativized choice functions - no matter whether defined as in (4) and (6)/(8), modified for partiality/totality, or implemented under the falsifying individual strategy--, fail to account for the local presupposition accommodation readings at issue.

I propose to generate these readings by using choice functions that do not yield individuals (type e), but individual concepts (type $<$ s,e $>$ ); that is, I propose to use intensional choice functions. A first definition is given under (21):

Intensional "Choice" Function: $\mathrm{f}_{<<\mathrm{e}, \mathrm{st}>\text {, }<\text { se }>>}$

(Heim 1994)

A function $\mathrm{f} \in \mathrm{D}_{<<\mathrm{e}, \mathrm{st}>\text {, }<\mathrm{se}>>}$ is an intensional choice function ( $\left.\mathrm{ICH}(\mathrm{f})\right)$ iff, for all $P$ in the domain of $f$ and for all $w$ in the domain of $f(P)$ :

$$
P(f(P)(w))(w)=1
$$

The crucial feature of intensional choice functions is that they provide another term to anchor the (to-be-locally-accommodated) existence presupposition. Instead of building partiality into the choice function itself -which we saw leads to weak truth conditions--, we make the value of the choice function -i.e., the individual concept-- partial. The formula representing the local presupposition accommodation reading is spelled out in (22b):

(22) a. Which pet of his ${ }_{1}$ did at most one boy 1 mistreat?

b. $\lambda w \lambda$ p. $\exists f\left[\operatorname{ICH}(f)(w) \& p=\lambda w^{\prime} \cdot \exists_{\leq 1} x\left[\operatorname{boy}(x)\left(w^{\prime}\right) \& \exists y[f(p e t\right.\right.$ of $x)$ $\left(w^{\prime}\right)=y \quad \&$ mistreat $\left.\left.\left.(y)(x)\left(w^{\prime}\right)\right]\right]\right]$ 
Are we deriving now only the desired local presupposition readings, with no overgeneration? The answer is yes. Take the intensional choice function sketched in (23) as one of the values for $f$. That makes the proposition (22c) a member of the question denotation. The sentence (22A) expresses precisely this proposition (possibly among others). Hence, $(22 \mathrm{~A})$ is correctly elicited as felicitous answer under its local presupposition accommodation reading.

(23) Example of total intensional choice function, $\mathrm{ICH}\left(\mathrm{f}^{*}\right)$ :

$\mathrm{f}^{*}$ : for all relevant individuals $\mathrm{x}$ :

$\mathrm{f}^{*}\left(\left[\left[\text { pet of } h i s_{1}\right]\right]^{\mathrm{gx} / 1}\right)=$ the partial individual concept "the pet of $\mathrm{x}$ that is X's dog",

$\mathrm{f}^{*}\left(\left[\left[\text { book of } \text { his }_{1}\right]\right]^{\mathrm{gx} / 1}\right)=$ the partial individual concept "the book of $\mathrm{x}$ that is X's latest book", etc.

c. $\lambda w^{\prime} \cdot \exists_{\leq 1} x\left[\operatorname{boy}(x)\left(w^{\prime}\right) \& \exists y\left[f^{*}(\right.\right.$ pet of $\left.\left.x)\left(w^{\prime}\right)=y \& \operatorname{mistreat}(y)(x)\left(w^{\prime}\right)\right]\right]$

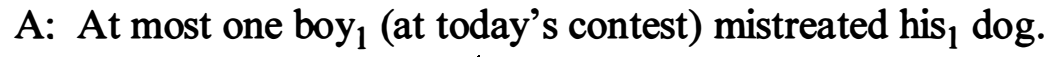

Now consider the functions sketched in (24) and (25), potential source of unfelicitous answers. (24) is immediately ruled out because the values for $f$ are explicitly restricted to intensional choice functions, and (24) is not one of them according to the definition (21). As for (25), we can rule it out by invoking a contextual restriction on sensible choice functions, so that only functions whose range contains plausible individual concepts are considered. Recall that this type of contextual restriction had no ground with extensional functions: the individual $\mathrm{H}$. Bogart is as pragmatically plausible as some particular dogs, and, hence, the corresponding functions choosing them are equally sensible. Pragmatic factors help us only with intensional choice functions.

$\mathrm{f}+$ : for all relevant individuals $\mathrm{x}$ : $\mathrm{f}+\left(\left[\left[\text { pet of } h i s_{1}\right]\right]^{\mathrm{gx} / 1}\right)=$ the constant individual concept "H. Bogart", etc.

$\mathbf{f}^{\wedge}$ : for all relevant individuals $\mathbf{x}$ :

$\mathrm{f}^{\wedge}\left(\left[\left[\text { pet of } h i s_{1}\right]\right]^{\mathrm{gx} / 1}\right)=$ the partial individual concept "the pet of $\mathrm{x}$ that is $\mathrm{H}$. Bogart", etc.

(Some version of) intensional choice functions is needed independently in order to account for examples like (26) (Engdahl 1980, 1986), where the NP in the answer is interpreted de dicto under the (elided) attitude verb believe. What I have proposed in this paper is to use intensional choice functions even when there is no embedded intensional operator involved. I have used them to generate local presupposition readings independently of embedded intensional contexts, but, of 
course, once this is so, it could be argued that we can use them independently of presupposition accommodation as well. I leave the latter issue open in this paper. ${ }^{10}$

Q: Which book did John believe that every author ${ }_{1}$ would read from?

A: From his ${ }_{1}$ latest one -whichever that may be.

(Engdahl 1986:167)

As a corollary, once we decide to use intensional choice functions even when no intensional operator intervenes, the problem of empty $\mathrm{N}^{\prime}$-restrictors does not even arise. Recall the oddity of example (7a), repeated as (27Q), and the two strategies used to confront it: to make choice functions partial (which we just saw leads to weak truth conditions) or to stipulate a special (trivially) falsifying value for empty N'-restrictors. With intensional choice functions, empty N'-restrictors are accounted for straighforwardly. For example, in (27), the question denotation $[[(27 \mathrm{Q})]]\left(\mathrm{w}_{0}\right)$ contains the proposition $(27 \mathrm{~b})$, which, in principle, elicits $(27 \mathrm{~A})$ as a felicitous answer. However, (27A) -and any other answer elicited by the question meaning (27a)-- is a case of presupposition failure: the presupposition that there is an oldest king of America projects to the top node of the declarative sentence, but it is not met in the actual/background world(s). The oddness of question (27A) is, hence, due to the lack of felicitous propositions that would count as answers in $\mathrm{w}_{0}$. This account avoids the shortcomings of the previous strategies.

Q:\# Who checked every law that which American king had sanctioned?

a. $\lambda \mathrm{w}_{1} \lambda \mathrm{p}: \exists \mathrm{g}, \mathrm{f}[\mathrm{ICH}(\mathrm{g}) \& \operatorname{ICH}(\mathrm{f}) \& \mathrm{p}=\lambda \mathrm{w} \cdot \forall \mathrm{x}[(\operatorname{law}(\mathrm{x})(\mathrm{w}) \&$ sanction $(\mathrm{x})(\mathrm{f}($ American king $))(\mathrm{w})) \rightarrow \operatorname{checked}(\mathrm{x})(\mathrm{g}($ person $))(\mathrm{w})]]$

b. $\lambda w . \forall x\left[\left(\operatorname{law}(x)(w) \&\right.\right.$ sanction $(x)\left(f_{\text {oldest }}(\right.$ American king $\left.\left.)\right)(w)\right) \rightarrow$ checked(x)(g(person) $)(w)]$

A: \# Martin checked every law that the oldest American king had sanctioned.

This concludes subsection 2.1. Individual concepts as the value of choice functions are needed independently in order to account for intensional answers, as we saw in (26). The conclusion of this subsection is simply that we need individual concepts more often than we thought, namely when there is no embedded intensional context. Once this is so, empty $\mathrm{N}^{\prime}$-restrictors do not need a special treatment. $^{11}$

\subsection{Transparent Which Phrases Eliciting Intensional Answers.}

This subsection presents data that call for a redefinition of intensional choice functions. I repeat the current definition under (28). According to this definition, the resulting individual concept $\underline{x}$ will necessarily assign each world $w$ in its domain to an individual that has the original property $\mathrm{P}$ in $\mathrm{w}$. To say it more intuitively, each property in the domain of the choice function is mapped onto a 
sort of "subconcept" of that property (e.g. [[red apple]] may be mapped to "the leftmost red apple", but not to "the leftmost apple").

Intensional "Choice" Function: $\mathrm{f}_{<<\mathrm{e}, \mathrm{st}>,<\mathrm{se}>>}$

A function $\mathrm{f} \in \mathrm{D}_{<<\mathrm{e}, \mathrm{st}\rangle,<\mathrm{se}>>}$ is an intensional choice function (ICH(f)) iff, for all $P$ in the domain of $f$ and for all $w$ in the domain of $f(P)$ :

$$
P(f(P)(w))(w)=1
$$

This characterization of intensional choice functions proves too narrow in view of the following examples. The intended readings, prompted by the corresponding scenarios, take the N'-restrictor of the which phrase as transparent with respect to want and the chosen individual concept as de dicto with respect to the same verb. ${ }^{12}$

(29) Scenario for (30):

Petra, an innocent four year old that simpathizes with old dogs, wants every friend of hers to play with the oldest dog in that friend's neighborhood, whatever that dog may be. Unbeknownst to her, rabies has affected all dogs, squirrels and raccoons in the surrounding neighborhoods.

Q: Which animal that may give him rabies does Petra want every friend $_{1}$ of hers to play with?

A: The oldest dog in his ${ }_{1}$ neighborhood --whichever that dog is.

(31) Scenario for (32):

Martin is looking for the Dean of the University of Barcelona, whoever that is. Martin does not know that such Dean is a civil servant depending on the Catalan Government (called "Generality") and not on the Spanish government. In fact, Martin has no beliefs about the Dean's affiliation nor has narrowed down the Dean's identity to any particular set of people.

Q: Which Generality civil servant does Martin want to talk to?

A: The Dean of the University of Barcelona -whoever that is.

The functions defined in (28) do not derive these readings. Let us see why with the last example. First, take the property [[Generality civil servant $]]^{\mathrm{g}}$, defined in (33), as the argument of one of those functions. The resulting individual concept may be "the Generality civil servant that is the Dean of the U.B.". Crucially, the "chosen" individual concept cannot be the individual concept "the Dean of the U.B.", since this concept maps each world w in its domain onto the Dean in w independently of the Dean's affiliation in w. Yet, it is precisely the latter concept that we need in order to generate the desired reading: Martin's desire worlds include worlds where the Dean is affiliated to the Generality and worlds where she/he is not, and Martin talks to the Dean in all of those worlds independently of the Dean's affiliation. 


\section{$\lambda w \lambda x$. Generality-civil-servant $(x)(w)$}

Similarly, if we take the property in (34) as the argument of one of those functions, we end up with the wrong individual concept as well. ${ }^{13}$ Let us pretend that, in the actual world $w_{0},\{a, b, c, d, e\}$ is the exhaustive set of Generality civil servants. The individual concept "chosen" out of that property will be "the individual in $\{a, b, c, d, e\}$ that is the Dean of the U.B.". Again, this is not the concept we are looking for, since Martin has not narrowed down the identity of the Dean to any particular set of people and, hence, his desire worlds should include worlds where the Dean is none of the actual Generality civil servants.

\section{$\lambda w \lambda x$. Generality-civil-servant $(x)\left(\mathbf{w}_{0}\right)$}

We need a new definition of intensional choice function. The possibility I will pursue in this paper splits the work done by the old definition into two components. ${ }^{14}$ For the first ingredient $-\mathrm{a}$ new definition of intensional choice functions--, I follow the basic notion of choice function but implement it with intensional types: basic intensional choice functions select an individual concept out of a set of individual concepts, as defined in (35):

Basic intensional choice function definition:

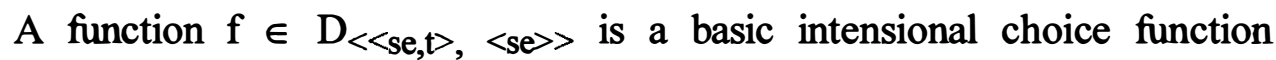
(BASICH(f)) iff for all $P$ in the domain of $f: P(f(P))=1$

As the second ingredient, I propose that some natural language expressions are ambiguous between a property of individuals meaning and a property of individual concepts meaning, as indicated in (36). For example, [[Generality civil servant $<\mathrm{s}$, et $>]]\left(\mathrm{w}_{0}\right)$ would be a set of individuals, and $[[$ Generality civil servant $<$, $\langle$ se,,$>>]]\left(w_{0}\right)$ would be a set of individual concepts, containing, among others, the concept "the Dean of the University of Barcelona".

[[Generality civil servant $]$ is ambiguous:

a. Property of individuals: type $<\mathrm{s},<\mathrm{e}, \mathrm{t}>>$

b. Property of individual concepts: type $<$ s, $<$ se,t $>>$

The question arises what determines, in a given world $w$, whether an individual concept belongs to $[[$ Generality civil servant $<\mathrm{s},<$ se,t>> $]](\mathrm{w})$ or not. In other words, what is the relation between the $<$ s,et $>$ meaning of Generality civil servant and its $<\mathrm{s},<\mathrm{se}, \mathrm{t}>>$ meaning, if any? Although the answer to this question and its justification fall beyond the aims of this paper, I will briefly speculate with some ideas for the reader to see how the system would work. Recall that we want to preserve the virtues that the original intensional choice function definition had in the previous subsection while allowing for the new set of examples. That is, our desiderata are the following: 
a. All proper "subconcepts" can be the output of a choice function, no matter whether the <s,et $>$ type denotation of the N'-restrictor happens to be empty in the relevant evaluation world or not. [Choice functions selecting implausible "subconcepts" are ruled out pragmatically.]

b. Some non-"subconcepts" cannot be selected by a choice function. E.g., if the N'-restrictor is pet of his 1 and, in the relevant evaluation world, the individual Humphrey Bogart is not a pet of $g(1)$, the choice function cannot yield the individual concept "Humphrey Bogart".

c. Some non-"subconcepts" can be selected by a choice function. E.g., if the N'-restrictor is Generality civil servant and, in the relevant world, the individual that is the Dean of the U.B. is also a Generality civil servant, the choice function can yield the individual concept "the Dean of the U.B."

Let us address our desideratum (37c) first, that is, let us make sure we are able to select the concept "the Dean of the U.B." simpliciter out of the set [[Generality civil servant $<$, $<$ se,,$>>]](\mathrm{w}), \mathrm{w}$ being the $\mathrm{N}$-bar's evaluation world. This can be achieved if we assume the relation in (38), which proposes a rather weak condition: in order for the individual concept to belong to that set, the value of the individual concept needs to have the relevant property just in the evaluation world. Hence, in a world $w$ where the person that is the Dean of the U.B. is a Generality civil servant, both the "subconcept" "the Generality civil servant that is the Dean of the U.B." and the concept "the Dean of the U.B." belong to that set, as desired.

(38) For any natural language expression $\mathrm{P}$ ambiguous between type $<$ s,et $>$ and type $<\mathrm{s},<\mathrm{se}, \mathrm{t}>>$, for any $\mathrm{w} \in \mathrm{D}_{\mathrm{s}}$, any $\underline{\mathrm{x}} \in \mathrm{D}_{<\mathrm{s}, \mathrm{e}>}, \quad$ [TO BE REVISED] $\left[\left[\mathrm{P}_{<\mathrm{s},<s e, t>>}\right]\right](\mathrm{w})(\underline{\mathrm{x}})=1 \quad$ iff $\quad\left[\left[\mathrm{P}_{<\mathrm{s},<\mathrm{e}, \mathrm{t}>>}\right]\right](\mathrm{w})(\underline{\mathrm{x}}(\mathrm{w}))=1$

So far, so good. But note that now we have partly flawded our desideratum (37a): we cannot generate proper "subconcepts" in the case of empty N'-restritors. To see this, consider what would count as an American king concept in the actual world. Intuitively, we might include the following: "the first American king", "the shortest American king", "the bastard American king", etc. None of these concepts belongs to $\left[\left[\right.\right.$ American $k_{\text {ing }}<$, $\left.\left.<\mathrm{se}, \mathrm{t}>>\right]\right]\left(\mathrm{w}_{0}\right)$ according to $(38)$, since none of these concepts is defined in $w_{0}$, to begin with.

What we need is an even weaker condition, where the relation between the individual concept $\underline{\mathrm{x}}$ and the $<\mathrm{s}$, et $>$ property holds in the evaluation world $\mathrm{w}$ if the $\underline{\mathbf{x}}$ is defined in $\mathrm{w}$, and in some other world otherwise. One possible implementation is that such relation must hold in the possible worlds most similar to the evaluation world $w$ where the individual concept is defined. This idea is spelled out in (39):

(39) For any natural language expression $P$ ambiguous between type $<$ s,et $>$ and type $<\mathrm{s},<$ se, $\mathrm{t}>>$, for any $\mathrm{w} \in \mathrm{D}_{\mathrm{s}}$, and for any $\underline{\mathrm{x}} \in \mathrm{D}_{<\mathrm{s}, \mathrm{e}}$, $\left[\left[\mathrm{P}_{<\mathrm{s},<\mathrm{se}, \mathrm{t}>>}\right]\right](\mathrm{w})(\underline{\mathrm{x}}) \quad$ iff $\forall \mathrm{w}^{\prime}\left[\left(\mathrm{w}^{\prime} \in \operatorname{Dom}(\underline{\mathrm{x}}) \& \mathrm{w}^{\prime}\right.\right.$ is similar to $\mathrm{w}$ otherwise $\left.) \rightarrow\left[\left[\mathrm{P}_{<\mathrm{s},<\mathrm{e}, \mathrm{t}>>}\right]\right](\mathrm{w})(\underline{\mathrm{x}}(\mathrm{w}))\right]$ 
Under (39), [[American king $\left.\left._{<\mathrm{s},<\mathrm{se}, t>>}\right]\right]\left(\mathrm{w}_{0}\right)$ contains the concept "the first American king", since, in the w' most similar to $\mathrm{w}_{0}$ where there is an individual that is the first American king, that individual is certainly an American king. That is, according to (39), proper "subconcepts" are always included in the denotation of an $<$ s, $<$ se,t $>>$ type restrictor, no matter whether the <et $>$ type denotation of that $\mathrm{N}$-restrictor in the evaluation world is empty or not. Therefore, our desideratum (37a) is now completely fulfilled.

Finally, let us make sure that the desideratum (37b) is met. Let us take a world w where Humphrey Bogart exists and is not a pet of $g(1)$. For the individual concept "Humphrey Bogart" to belong to and, thus, be selectable from [[pet of $\left.h i s_{1<s,<s e, t>>}\right]^{\mathrm{g}}(\mathrm{w})$, the following would have to hold: in the world w' most similar to $\mathrm{w}$ where Humphrey Bogart exists -i.e., in w itself--, the individual Humphrey Bogart is a pet of $g(1)$ in w' -i.e., in w itself. By assumption, this is not the case, and, hence, this non-"subconcept" cannot be selected by a choice function out of $\left[\left[\text { pet of his } s_{1<s,<s e, t>>}\right]\right]^{\mathrm{g}}(\mathrm{w})$.

Let me recapitulate the import of this subsection. We started with Heim's (1994) definition of intensional "choice" functions, which had yielded good results in the previous section. Then, examples of transparent which phrases eliciting intensional answers motivated a revision. I proposed a more liberal definition, where basic intensional choice functions select an individual concept out of the $<$ se,t $>$ type denotation of an N'-restrictor. I also sketched a possible way to relate $<$ s, $<$ se,t $>>$ meanings and $<$ s,et $>$ meanings so that the accomplishments of the original intensional choice function approach would be preserved and the new data could be derived.

To conclude, this entire section 2 has proposed some changes in the architecture (semantic type and definition) of choice functions: we need choice functions that yield individual concepts even in questions with no embedded intensional context, so as to derive the local presupposition data; such functions must also derive intensional answers for which phrases with transparent N'restrictors, a goal for which I have suggested a possible analysis.

\section{Indicators of opaque N'-restrictor: Spanish Subjunctive Relative Clauses}

This section is concerned with another aspect of some current choice function implementations, namely what I have dubbed "Transparency Effect". As advanced at the beginning of this paper, Reinhart $(1992,1997)$ observes that the choice function in (40) must select an individual from the $\mathrm{w}_{0}$-extension of philosopher; it cannot choose an individual that has the relevant property only in the conditional worlds:

(40) Q: Who will be upset if we invite which philosopher? (Reinhart 1992:(4))

A: Pat will be upset if we invite David Lewis.

A': \# Pat will be upset if we invite Donald Duck. 
Spanish qué-phrases show the same Transparency Effect in (41). However, there are some indicators in Spanish that N'-restrictors of which phrases are not necessarily transparent, i.e., that choice functions may sometimes choose from the extension of the N'-restrictor in some embedded intensional context world. The aim of this section is to present those Spanish data and, hence, to shed some suspicion on the current explanation for the Transparency Effect, ie., on relativized choice functions. I will leave alternative explanations for future research.

Q: Quién se enfadará/enfadaría si invitamos/invitásemos a qué filósofo? Who will/would-be-upset if we invite/invited which(/what) philosopher A': \#Patricia se enfadará/enfadaría si invitamos/invitásemos al Pato Donald. Patricia will/would-be-upset if we invited the Donald Duck

In Spanish, mood in Relative Clauses (RCs, henceforth) correlates with their w-interpretation under certain intensional contexts (e.g., conditionals and desire attitudes) (Farkas 1997, Quer 1998). Indicative RCs, on the one hand, are interpreted as transparent with respect to those intensional contexts, as in (42): the DP at least 100 people that are rich takes scope inside the if-clause, and the Indicative $\mathrm{RC}$ is evaluated in the actual world $\mathrm{w}_{0}$. Subjunctive RCs, on the other hand, are opaque, as (43) shows: Subjunctive forces us to evaluate the RC in the conditional worlds, which renders (43a) pragmatically non-sensical; once this pragmatic oddity is removed, the construction is fine $((43 \mathrm{~b})):^{15}$

Sería feliz si al menos 100 personas que son-Ind ricas fuesen pobres. I-would-be happy if at least 100 people that are-Ind rich were poor

(from Farkas' example in English)

a.\#Sería feliz si al menos 100 personas que fuesen-Sub ricas fuesen pobres.

b. Sería feliz si al menos 100 personas que fuesen-Sub ricas donasen

I-would-be happy if at least 100 people that were-Sub rich gave parte de su fortuna a los pobres. part of their fortune to the poor

The first point I would like to make is that Subjunctive RCs can modify which phrases too, yielding the same opacity symptoms as in other DPs. Compare the Indicative (44a) and the Subjunctive (44b). According to the former, there has to be a non-empty set that fulfills the $\mathrm{N}$ '-description in $\mathrm{w}_{0}$, though the subject Tomás may not think that that set of people has that property. In the latter, there need not be anybody fulfilling the N'-property in the actual world, but certainly there has to be somebody like that in Tomás' doxastic/bouletic alternatives.

a. Q: [ A qué chica ${ }_{2}$ que (no) se acuerda-Ind de él ${ }_{1}$ ] quiere To which(/what) woman that (not) REFL remember of him wants Tomás $_{1}$ que le $_{2}$ pidas el número de teléfono? Tomás that CL ask-2sg-Subj the number of telephone 
'Which woman $_{2}$ that (doesn't) remember(s) him 1 does Tomás want you to ask for her ${ }_{2}$ phone number?'

A: A Claudia. 'Claudia'

b. Q: [A qué chica 2 que se acuerde-Sub de él ${ }_{1}$ quiere Tomás ${ }_{1}$ que le $_{2}$ pidas el número de teléfono?

A: A la más simpática -quienquiera que sea.

'The neatest one-whoever that is.'

The contrast Indicative/Subjunctive tells us something about the winterpretation of the $\mathrm{RC}$, not about whether the requested answer should be extensional (de re) or intensional (a de dicto individual concept). This can be seen in (45): transparent RCs in which phrases with intensional answers use Indicative.

Q: [Con qué animal que puede-Ind contagiarles la rabia] quiere

With which/what animal that may give-them the rabies] wants

Mónica que todos sus amigos jueguen?

Mónica that all her friends play-Subj.

'With which(/what) animal that may give them rabies does

Mónica want all her friends to play?'

A: 'With the oldest dog in the neighborhood - whatever that dog may be.'

The second point of this section is that, although the Transparency Effect often obtains, examples with Subjunctive RCs can be constructed where this effect is overriden: in contrast with (41), the answer to (46) does not presuppose that Paco is about to get married in $\mathrm{w}_{0}$; he is an imminent groom only in the conditional worlds. This reading of (46) is formalized in (47a), and the relevant aspects of the choice function are described in (47b).

(46) Q: [Quién se enfadaría si qué familiar suyo que estuviera-Sub a punto Who would-be-upset if which relative of-his that was-Sub about de casarse] no le llamara para decírselo?

to-get-married not him/her called to tell-him/her

'Who ${ }_{1}$ would be upset if which/what relative of his ${ }_{1}$ that was-Sub

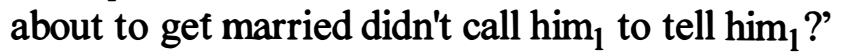

A: Pedro se enfadaría si su primo Paco estuviera a punto de casarse y no le llamara para decírselo.

'Peter would be upset if his cousin Paco was about to get married and didn't call him to tell him.'

a. $\lambda w \lambda$ p. $\exists \mathrm{g}, \mathrm{f}\left[\mathrm{BASICH}(\mathrm{g}) \& \operatorname{BASICH}(\mathrm{f}) \& \mathrm{p}=\lambda \mathrm{w}^{\prime} \cdot \forall \mathrm{w}^{\prime \prime}\left[\exists \mathrm{x}\left[\mathrm{f}\left(\left[\left[r-h i s_{1}\right.\right.\right.\right.\right.\right.$ -marry $\left.\left._{<<<\text {se },>>}\right] \mathrm{g}\left(\mathrm{w}^{\prime \prime}\right)\right)\left(\mathrm{w}^{\prime \prime}\right)=\mathrm{x} \& \neg$ call $\left(\mathrm{g}([[\right.$ person $\left.]](\mathrm{w}))\left(\mathrm{w}^{\prime \prime}\right)\right)(\mathrm{x})\left(\mathrm{w}^{\prime \prime}\right)$ $\& w^{\prime \prime}$ is like $w^{\prime}$ otherwise $\rightarrow$ upset $(g([$ person $\left.\left.\left.]](w))\left(w^{\prime \prime}\right)\right)\left(w^{\prime \prime}\right)\right]\right]$

b. For all the w" in which the antecedent of the conditional holds: $\mathrm{f}\left(\left[\left[\right.\right.\right.$ relative of his $_{1}$ about to get married $\left.\left.\left._{<\mathrm{s}<\mathrm{se}, \mathrm{t}>>}\right]\right] \mathrm{g}\left(\mathrm{w}^{\prime \prime}\right)\right)=$ "the relative of $\mathrm{g}(1)$ about to get married that is $\mathrm{g}(1)$ 's cousin Paco", or, "g(1)'s cousin Paco". 
In sum, Spanish qué-phrases, like English which-phrases, often yield Transparency Effects. However, we have seen that they take opaque Relative Clauses as restrictors and that, sometimes, the Transparency Effect is overriden. This suggest that choice functions for which phrases are not committed to select from the extension of the N'-restritor in the evaluation world of the question, as the relativized choice function approach proposed. Instead, they may choose from the N'-extension in some other embedded worlds, possibility that the basic choice function line allows for.

\section{Conclusions}

This paper has argued for a wider distribution of intensional choice functions for which phrases, and for a basic choice function implementation of them. First, from data on local presupposition accommodation, I concluded that we have intensional choice functions more often than we thought. As a corollary, the problem of empty $\mathrm{N}$-restrictors disappears. Second, based on data on transparent which-phrases eliciting intensional answers, I proposed to reformulate intensional choice functions in terms of the basic choice function idea: an intensional choice function chooses an individual concept out of a set of individuals concepts. Third, with data on Spanish Subjunctive Relatives, I have shown that the Spanish correlates of which (or what) phrases may take opaque restrictors. This casts doubt on an account that handles the Transparency Effect as a grammatical fact (i.e., on relativized choice functions); the basic choice function line is, thus, preferrable.

\section{Endnotes}

* I thank I. Heim, A. Kratzer and B. Partee for their valuable comments at several stages of this paper. The final version has also benefitted from the audiences at Umass, the MIT LF-group, IRCS at Penn, and SALT 9. Remaining erros are mine.

${ }^{1}$ Actually, Karttunen's question denotation in a given $\mathrm{w}$ is the set of felicitous true answers of the described shape; i.e. the formula $p(w)$ would be inserted within (1b). This detail is tangential to the present paper.

${ }^{2}$ (2c) would even count as (trivially) true answer if philosopher is evaluated in w.

3 The alternative wide scope line uses skolem functions instead. For data suggesting that the base position line is empirically superior, see Fox (1997) and Romero (forth.) (variable binding produces Principle C Connectivity Effects) and Ruys (1992) (distributive readings out of islands are impossible for indefinites, an argument that is extensible to which-phrases).

${ }^{4}$ More accurately, which would not range over choice functions, but over functions from individuals to choice functions, as Kratzer (1998:168) proposes for a certain. I will ignore this detail for the purposes of this paper.

${ }^{5}$ I freely switch between sets and their characteristic functions. 
6 This is so in Bochvar's three-valued logic. In Kleene's system, the prediction is that (7a) denotes in $w_{0}$ the set of propositions $p$ that have the following characteristic: for a given choice function $g, p$ is such that, for any $w^{\prime}, p\left(w^{\prime}\right)=1$ if $\mathrm{g}$ (person) checked absolutely all the laws in w', and undefined otherwise.

${ }^{7}$ In the RCH approach, $f($ American king) abbreviates $f([$ American king (As,et $]]$ ).

${ }^{8}$ Beaver (1995:214) provides examples similar to (9), e.g. (i), which he concedes is compatible with there being no priceless Modigliani owners. He notes that this type of local presupposition arises from presupposition triggers containing a bound variable pronoun. Since his semantic rules do not derive this reading and I do not know of any other solution, I will consider that it arises from local presupposition accommodation (in the sense of Heim 1983) within the quantifier's nuclear scope. (i) No man discovered / regretted that he owned a priceless Modigliani.

${ }^{9}$ Exactly the same reasoning applies to partial basic choice functions. The only difference is that, with basic functions, we could also evaluate the N'-restrictor under w' in the formulae (17b-c-d) and generate what Groenendijk-Stokhof (1982) call de dicto reading. The same weak truth conditions obtain.

${ }^{10}$ A potential example of intensional answer without embedded intensional context and without local presupposition accommodation is (iQ)-(iA') (cf. (iA)):

(i) Q: Who won the Tour de France in 1980?

(G\&S 1982:228)

A: Joop Zoetemelk.

$A^{\prime}$ : The one who ended second in 1979.

Groenendijk-Stokhof (1982) consider that the extensional answer (iA) is somehow part of the denotation of the question, but that the seemingly intensional (iA') is not; the latter is elicited indirectly, under some extended notion of answerhood. If we extend the findings of our paper to questions with no local presupposition accommodation, (iQ) has a question denotation that elicits (iA') directly.

11 Much of what I have said in this subsection 2.1 applies to the so-called "specific" indefinites and their analysis in terms of choice functions (Reinhart 1997, Winter 1997, Kratzer 1998). Space constraints keep me from elaborating on it.

12 I assume that the definite description the oldest dog in his neighborhood in (30A) does not result from a choice function selecting a kind, since singular definite descriptions can only refer to standardly recognized kinds (e.g., the bottle, but not the green bottle) (Carlson 1977). The same considerations extend to (32) (the reader may take the DP the shortest Dean of the U.B. if she prefers so).

${ }_{13}$ I thank Angelika Kratzer for suggesting that I try this possibility.

14 What I will present is just one possibility, but certainly others come to mind. For instance, if we accept that a subject can have a de re attitude not just towards an individual but also towards an individual concept (see Sharvit 1998), we may implement Heim's intensional "choice" function definition with higher types and obtain the desired results. I leave this possibility open for further research.

15 Giannakidou (1998) argues that, in Modern Greek, what Subjunctive indicates is non-veridicality, and that the Greek $\mathrm{RC}$ correlation Indicative-de $r e$ and Subjunctive-de dicto is a by-product of that (p. 91). Although it might be possible to derive the Spanish correlation Indicative-transparent and Subjunctive-opaque 
from non-veridicality as well (despite of some important differences: Greek definite DPs (Giannakidou (1998:90) and which-phrases (Giannakidou, p.c.) do not accept Subjunctive RCs, as opposed to Spanish), the relevant fact is the correlation itself.

\section{References}

Beaver, D. 1995. Presupposition and Assertion in Dynamic Semantics. Ph.D. Diss., University of Edinburgh.

Carlson, G. 1977. Reference to Kinds in English. Amherst: GLSA.

Engdahl, E. 1980. The Syntax and Semantics of Questions in Swedish. Amherst: GLSA.

Engdahl, E. 1986. Constituent Questions. Dordrecht: Kluwer.

Farkas, D. 1997. Evaluation indices and scope. In: A. Szabolcsi (ed.), Ways of scope taking. Drodrecht: Kluwer.

Fox, D. 1997. Reconstruction, Binding Theory and the Interpretation of Chains. MIT ms.

Giannakidou, A. 1998. Polarity Sensitivity as (Non) Veridical Dependency. John Benjamins.

Groenendijk, J.-Stokhof, M. 1982. Semantic analysis of $w h$-complements. $L \& P 5$.

Hamblin, C. 1973. Questions in Montague English. Foundations of Language 10.

Heim, I. 1983. On the projection problem of presuppositions. In: D. Flickinger et al. (eds.), Proceedings of WCCFL II. Stanford: Stanford University Press.

Heim, I. 1992. Presupposition Projection and the Semantics of Attitude Verbs. Journal of Semantics 9.

Heim, I. 1994. UMass lecture notes on Questions.

Karttunen, L. 1977. Syntax and Semantics of Questions. L\&P 1.

Kratzer, A. 1998. Scope or Pseudoscope? Are there Wide-Scope Indefinites? In:

S. Rothstein (ed.), Events and Grammar. Dordrecht: Kluwer.

Matthewson, L. 1999. On the interpretation of wide-scope indefinites. NLS 7.

Quer, J. 1998. Mood at the Interface. Ph.D. Diss., Utrecht Institute of Linguistics.

Pinkal, M. 1995. Logic and Lexicon. The Semantics of the Indefinite. Kluwer.

Reinhart, T. 1992. Wh-is-situ: An apparent paradox. In: P. Dekker et al. (eds.) Proceedings of the 8th Amsterdam Colloquium.

Reinhart, T. 1997. Quantifier scope: how labor is divided between QR and choice functions. $L \& P 20$.

Romero, M. 1997. A problem for choice functions: local presupposition contexts. In: P. Dekker et al.(eds.) Proceedings of the 11th Amsterdam Colloquium.

Romero, M. (forth.). Focus and Reconstruction Effects in Wh-Phrases. UMass Ph. D. Diss. Amherst: GLSA.

Ruys, E. G. 1992. The Scope of Indefinites. Ph.D. Diss., Utrecht University.

Sharvit, Y. 1998. Individual concepts and attitude reports. Talk at SALT 8.

von Stechow, A. 1996. Some remarks on choice functions and LF-movement. University of Tübingen $\mathrm{ms}$.

Winter, Y.1997. Choice functions and the scopal semantics of indefinites. $L \& P 20$. 